\title{
Analisis Perilaku Balok Kastella Dengan Variasi Jenis Bukaan
}

\author{
Richard Frans \\ Universitas Atma Jaya Makassar, Jalan Tanjung Alang, Makassar \\ E-mail: richardfrans.rf@gmail.com
}

Received 19 May 2020; Reviewed 03 September 2020; Accepted 09 October 2020

Journal Homepage: http://jurnal.borneo.ac.id/index.php/borneoengineering

\begin{abstract}
The main advantage of castellated beam is the increasing of bending capacity caused by the increasing of inertia moment of steel section due to the increasing of depth of the steel section. In addition, some people argue that the opening section of castellated beam become an additional advantage in terms of aesthetics view. In general, there are three opening variations that are very often used in construction, which are hexagonal opening, circular opening, and diamond opening. Many researches have been done to compare the performance of castellated beam with various opening but only focusing on the behavior of castellated beam subjected to monotonic loading. Therefore, in this research, a review of the behavior of castellated beam with various opening subjected to quasi-static cyclic loading was carried out in order to find out which is better performance from the opening variations. A finite element analysis was conducted to find out the behavior of castellated beam with three variations of opening. A simple beam subjected to quasi-static loading using displacement control technique was considered in this research. The result shows that the castellated beam with diamond opening has a better performance compared to the other openings (hexagonal opening and circular opening).
\end{abstract}

Keywords: castellated beam, hexagonal opening, circular opening, diamond opening, quasi-static cyclic loading

\begin{abstract}
Abstrak
Keunggulan utama dari balok kastella adalah peningkatan kapasitas lentur yang disebabkan oleh peningkatan momen inersia dari penampang akibat pertambahan tinggi dari profil balok tersebut. Selain itu, beberapa orang berpendapat, model penampang yang mempunyai variasi bukaan menjadi keunggulan tersendiri dari segi estetika. Secara umum, terdapat tiga jenis variasi bukaan yang sangat sering dijumpai dan digunakan dalam dunia konstruksi yaitu, balok kastella dengan bukaan heksagonal, bukaan circular, dan bukaan diamond. Telah banyak penelitian yang dilakukan untuk membandingkan kinerja balok kastella dengan variasi bukaan, akan tetapi pada umumnya berfokus pada perilaku balok kastella terhadap beban monotonik (beban satu arah). Oleh karena itu, pada penelitian ini, peninjauan perilaku balok kastella dengan variasi bukaan terhadap beban siklik quasistatik dilakukan dengan tujuan untuk mendapatkan variasi bukaan yang memiliki kinerja terbaik. Analisis elemen hingga digunakan untuk mendapatkan perilaku dari balok kastella dengan tiga variasi bukaan. Pada penelitian ini, struktur balok yang ditinjau adalah balok di atas dua tumpuan sederhana yang dibebani secara siklik quasi-statik dengan teknik kontrol perpindahan. Hasil yang didapatkan adalah balok kastella dengan bukaan diamond memiliku kinerja yang lebih baik jika dibandingkan dengan kedua bukaan lainnya (bukaan heksagonal dan bukaan circular).
\end{abstract}

Kata kunci: balok kastella, bukaan heksagonal, bukaan circular, bukaan diamond, beban siklik quasistatik 


\section{Pendahuluan}

Dewasa ini, material konstruksi yang sangat sering dijumpai dalam berbagai proyek infrastruktur adalah beton, baja, kayu ataupun komposit dari ketiganya (beton bertulang, baja komposit, kayu komposit dan lain-lain). Material-material ini merupakan komponen struktur utama dalam menopang beban-beban yang terjadi pada infrastruktur tersebut khususnya material beton dan baja, akan tetapi material baja lebih unggul jika dibandingkan dengan material konstruksi lainnya (beton maupun kayu) dari segi kekuatan, kekakuan, dan daktailitas (Frans dkk, 2018; Dewobroto, 2018; Ravi dan Aiswarya, 2018). Salah satu tipe balok baja yang sedang populer untuk digunakan dalam dunia konstruksi adalah balok kastella (Rugge dan Pasnur, 2017). Balok kastella merupakan balok baja yang mempunyai bukaan (lubang) pada bagian pelat badannya (web). Balok kastella dibentuk dengan memotong pada garis tengah sebuah balok baja profil I (hot rolled) menjadi dua bagian kemudian diangkat dan disatukan kembali dengan menggunakan las sehingga tinggi profil dapat bertambah 50\% yang berguna untuk menambah kapasitas lentur dari balok tersebut (Wakchaure dan Sagade, 2012; Govindrao dan Rahti, 2017; Deshmukh dan Kasnale, 2019). Keuntungan lain dari penggunaan balok kastella adalah bukaan (lubang) pada bagian pelat badan dapat digunakan untuk melewatkan saluran-saluran pipa dan keperluan ducting (Soltani dkk, 2012). Secara umum, terdapat beberapa bentuk bukaan dari balok kastella yang sering dijumpai dan telah banyak dilakukan pengujian terhadap kapasitas dari bentuk-bentuk bukaan tersebut, yaitu heksagonal, circular, dan diamond. Jamadar dan Kumbhar (2015) telah melakukan penelitian secara numerik dan eksperimental dengan membandingkan balok kastella dengan variasi jenis bukaan. Beban yang diberikan adalah beban monotonik. Dari hasil yang didapatkan, balok kastella dengan bukaan diamond memiliki kemampuan (kapasitas) yang lebih tinggi jika dibandingkan dengan balok kastella dengan bukaan lainnya (heksagonal dan circular). De'nan dkk (2017) melakukan penelitian untuk membandingkan kapasitas lentur dari balok kastella dengan lima variasi bukaan, yaitu model bukaan c-heksagon, heksagon, octagon, circle, dan kotak. Dari hasil yang didapatkan, balok kastella dengan bukaan c-heksagon mempunyai kapasitas yang lebih baik jika dibandingkan dengan bukaan lainnya. Panedpojaman dan Rongram (2014) mengusulkan persamaan untuk mendesain balok kastella dengan bukaan circular yang dominan terhadap mekanisme lentur Vierendeel, dan masih banyak penelitian-penelitian lainnya mengenai kapasitas kinerja dari balok kastella. Pada penelitian ini, perilaku balok kastella dengan variasi bukaan (bukaan heksagonal, bukaan circular, dan bukaan diamond) akan ditinjau terhadap beban siklik quasi-statik, sehingga dapat disimpulkan bukaan mana yang memiliki kinerja yang paling baik terhadap beban siklik quasi-statik.

\section{Metode Penelitian}

\subsection{Model Pengujian}

Penelitian menggunakan pemodelan elemen hingga dengan menggunakan bantuan perangkat lunak ABAQUS. Terdapat tiga variasi bukaan yang akan diuji, yaitu balok kastella dengan bukaan heksagonal, circular, dan diamond. Sebelum ketiga balok kastella ini dimodelkan secara elemen hingga, dilakukan optimasi terlebih dahulu untuk mendapatkan kriteria penampang yang optimum (Frans dkk, 2016). Kriteria yang dimaksudkan adalah geometri penampang yang mencakup rasio tinggi bukaan, sudut bukaan, dan jarak antar bukaan dari balok kastella. Struktur balok yang digunakan adalah struktur balok di atas dua tumpuan sendi. Untuk pemodelan elemen, terdapat beberapa elemen yang dapat dipilih dalam ABAQUS seperti yang terlihat pada Gambar 1. 


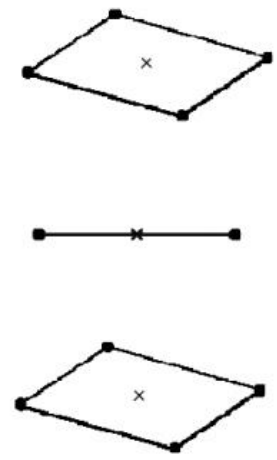

S4R: Shell, 4-node, Reduced integration

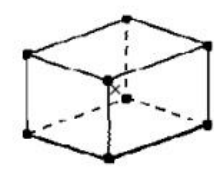

C3D8R: Continuum,

3-D, 8-node,

Reduced integration

B31: Beam, 3-D,

1st-order interpolation

M3D4R: Membrane,

3-D, 4-node,

Reduced integration

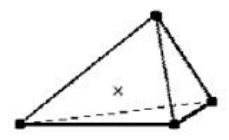
3-D, 4-node
C3D4: Continuum,

\section{Gambar 1. Tipe elemen dalam ABAQUS (ABAQUS, 2005)}

Elemen yang digunakan dalam penelitian ini adalah elemen S4R (shell-4 nodes with reduced integration). Pemodelan dengan menggunakan elemen S4R memberikan hasil yang cukup memuaskan dimana hasil pemodelan elemen hingga yang didapatkan hampir sama dengan hasil yang didapatkan dari model eksperimental (Rodrigues dkk, 2014; Frans dkk, 2017). Balok kastella yang digunakan berasal dari parent beam yaitu balok WF200 (Gambar 2). Pengambilan profil balok WF 200 mengacu pada penelitian-penelitian sebelumnya (Frans dkk, 2017; Frans dkk, 2018). Gambar 3 menunjukkan struktur balok di atas dua tumpuan sendi yang diuji sedangkan Gambar 4 menunjukkan geometri balok kastella dengan masing-masing bukaan yang telah dioptimasi. Model material yang digunakan adalah elasto-perfect plastic. Pembebanan yang digunakan menggunakan modul "step static-general" dengan penambahan beban yang sesuai dengan protokol pembebanan

yang digunakan.

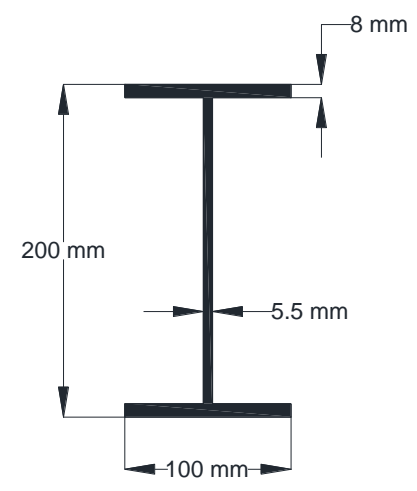

Gambar 2. Parent beam (profil WF200)

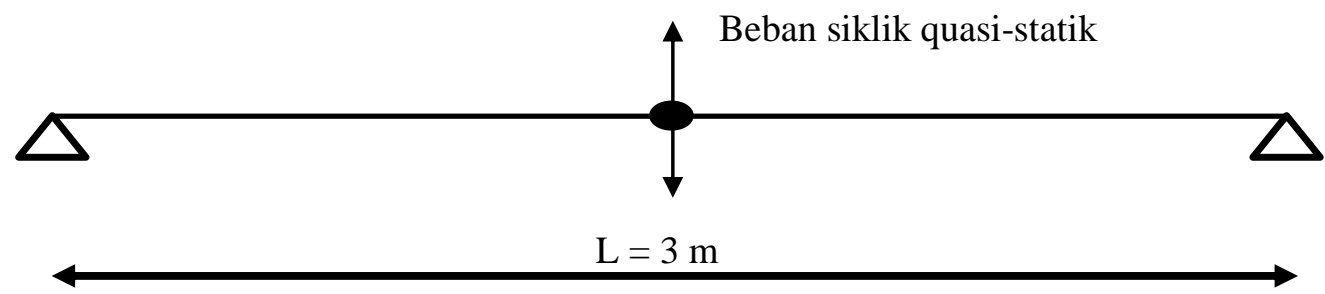

Gambar 3. Struktur balok yang ditinjau 


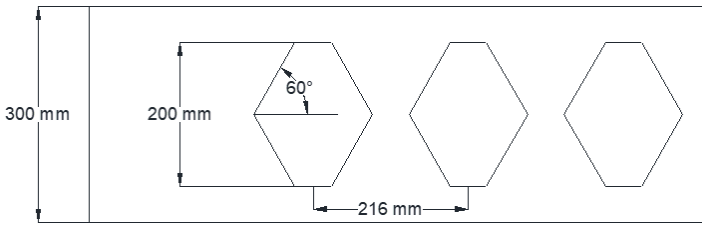

(a)

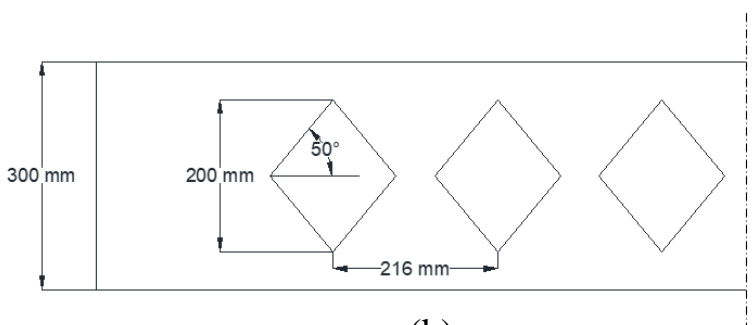

(b)

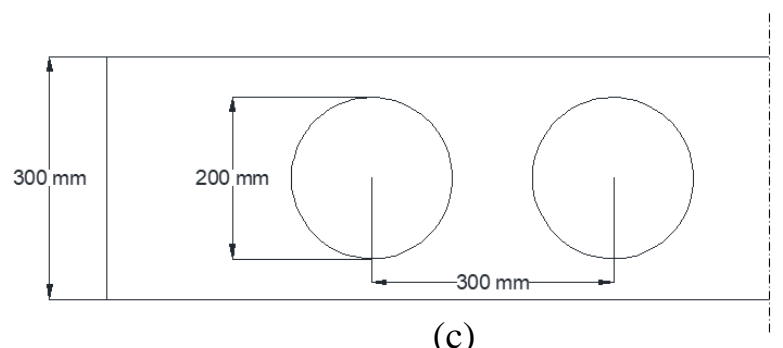

(c)

Gambar 4. Geometri balok kastella dengan bukaan, (a). heksagonal, (b). diamond, (c). circle

Tabel 1 menunjukkan karakteristik material yang digunakan pada pemodelan elemen hingga. Tipe material diasumsikan sebagai material elasto-plastic.

Tabel 1. Properti material yang digunakan

\begin{tabular}{ll}
\hline Modulus Elastisitas & $200.000 \mathrm{MPa}$ \\
\hline Poisson ratio & 0,3 \\
\hline Tegangan leleh & $320 \mathrm{MPa}$ \\
\hline
\end{tabular}

\subsection{Riwayat Pembebanan}

Pola pembebanan yang digunakan pada penelitian ini adalah pembebanan secara siklik quasi-statik dengan sistem kontrol perpindahan (displacement control). Pembebanan quasi-statik adalah pemberian beban secara perlahan dan terkontrol terhadap suatu struktur, sehingga deformasi akibat efek dinamis dari beban tersebut dapat diabaikan atau dengan kata lain gaya inersia yang bekerja pada sistem tersebut dapat diabaikan (FEMA 461, 2007). Prosedur pemberian beban siklik quasistatik yang digunakan dalam penelitian ini mengikuti protokol yang diberikan oleh ATC-24. Perpindahan leleh $\left(\Delta_{\mathrm{y}}\right)$ menjadi variabel acuan untuk pemberian beban. Menurut ATC-24, pemberian beban siklik quasi-statik mengikuti ketentuan berikut, yaitu: enam siklus elastis dimana nilai perpindahan yang diambil lebih kecil dari perpindahan leleh dari struktur tersebut $\left(\Delta<\Delta_{\mathrm{y}}\right)$ kemudian diikuti masing-masing tiga siklus untuk nilai perpindahan yang sama dengan perpindahan leleh $\left(\Delta_{\mathrm{y}}\right)$, nilai perpindahan yang besarnya dua kali perpindahan leleh $\left(2 . \Delta_{\mathrm{y}}\right)$, dan nilai perpindahan yang besarnya tiga kali perpindahan leleh $\left(3 . \Delta_{\mathrm{y}}\right)$. Setelah itu, pemberian beban diberikan secara bertahap dengan menambahkan perpindahan sebesar perpindahan leleh sebanyak dua siklus sampai terjadi kerusakan siklik pada struktur tersebut (ATC-24, 1992). Gambar 5 menunjukkan contoh riwayat pembebanan mengikuti protocol ATC-24. 


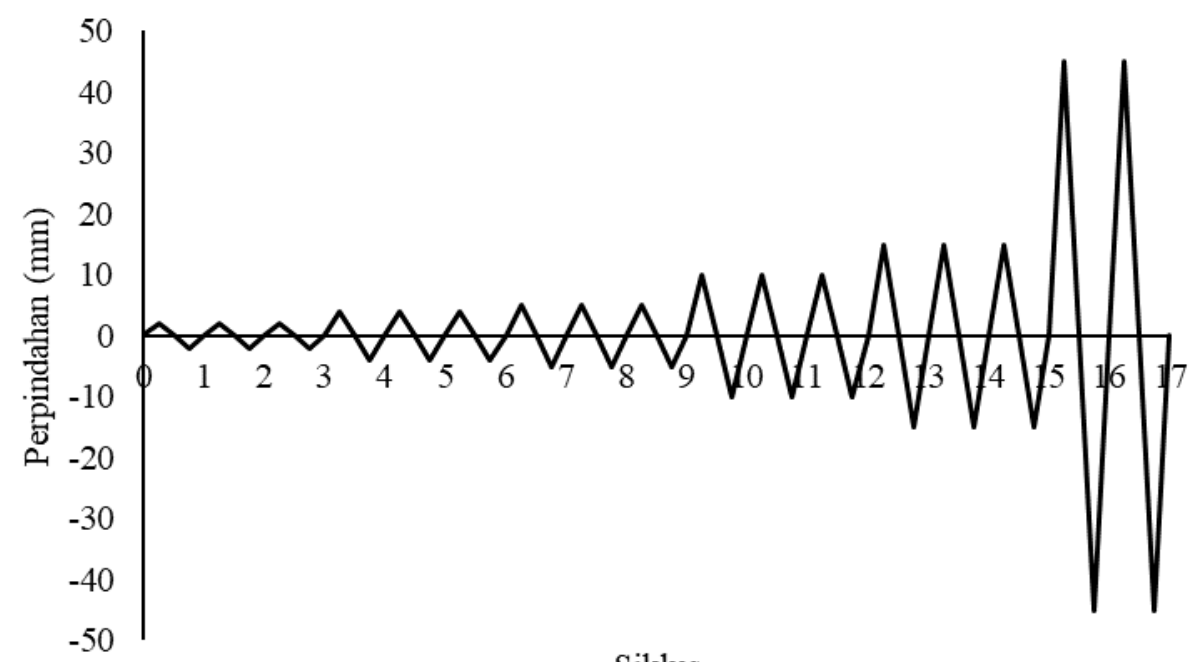

Gambar 5. Riwayat pembebanan berdasarkan ATC-24 (Krawinkler, 2009)

\section{Hasil dan Pembahasan}

Pengujian dimulai dengan pembebanan monotonik dikarenakan untuk melaksanakan pengujian dengan beban siklik quasi-statik berdasarkan ATC-24, nilai perpindahan leleh dari struktur harus diketahui terlebih dahulu untuk membentuk kurva riwayat pembebanan (loading history). Pembebanan monotonik yang dilakukan dengan skema pengujian yang hampir sama dengan Gambar 3 hanya saja beban yang bekerja di tengah bentang adalah beban monotonik yaitu beban satu arah. Pembebanan monotonik dilakukan terhadap ketiga variasi balok kastella (Gambar 4) untuk mendapatkan nilai perpindahan leleh dari masing-masing variasi bukaan. Gambar 6 menunjukkan hubungan antara perpindahan dan gaya reaksi (reaction force) untuk masing-masing variasi bukaan dan Tabel 2 menunjukkan nilai perpindahan leleh, gaya reaksi leleh, dan kekakuan struktur dari ketiga variasi bukaan.

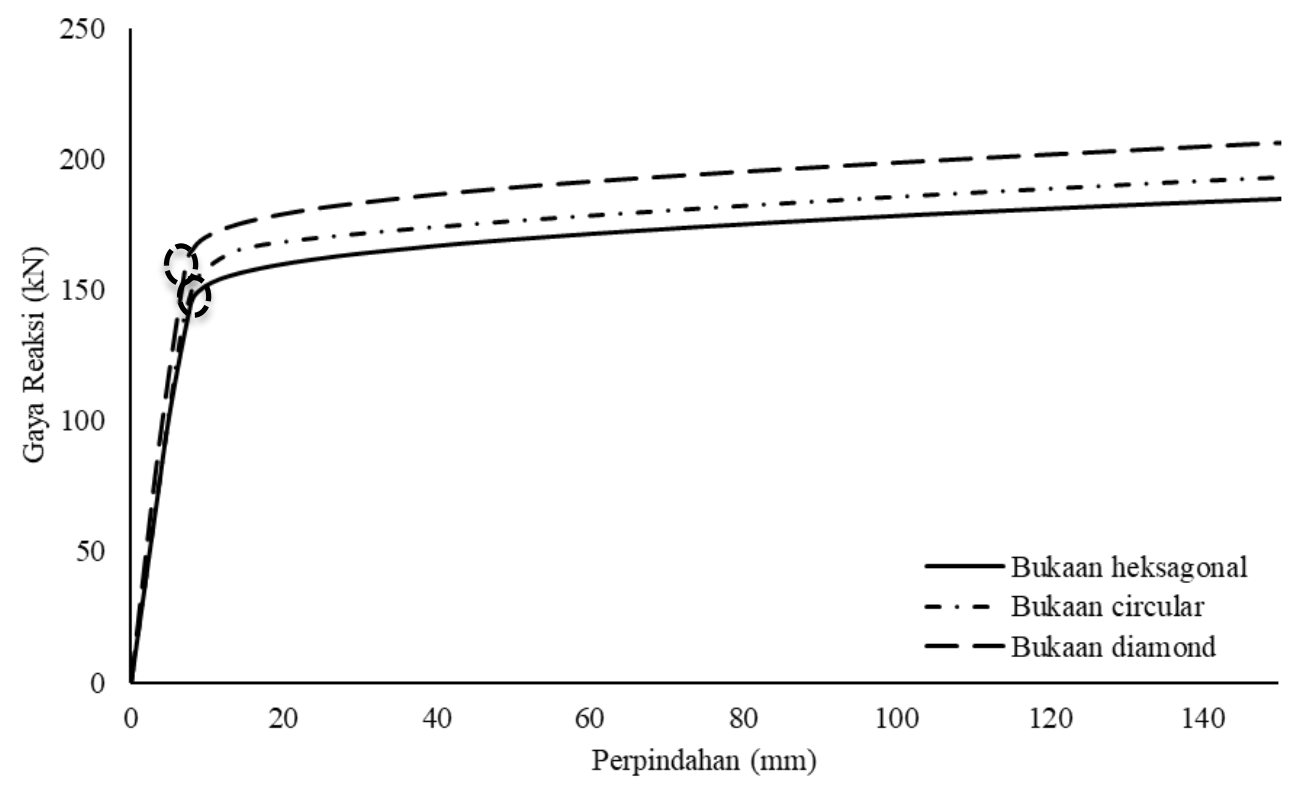

Gambar 6. Hubungan antara perpindahan dan gaya reaksi untuk ketiga variasi bukaan 
Tabel 2. Nilai perpindahan leleh, gaya reaksi leleh, dan kekakuan balok kastella terhadap beban monotonik

\begin{tabular}{cccc}
\hline Variabel yang ditinjau & $\begin{array}{c}\text { Bukaan } \\
\text { heksagonal }\end{array}$ & $\begin{array}{c}\text { Bukaan } \\
\text { circular }\end{array}$ & $\begin{array}{c}\text { Bukaan } \\
\text { diamond }\end{array}$ \\
\hline Perpindahan leleh $(\mathrm{mm})$ & 7,84 & 8,13 & 7,2 \\
Gaya reaksi leleh $(\mathrm{kN})$ & 145,85 & 151,98 & 160,8 \\
Kekakuan struktur $(\mathrm{kN} / \mathrm{mm})$ & 18,6033 & 18,6937 & 22,3333 \\
\hline
\end{tabular}

Berdasarkan Gambar 6 dan Tabel 2, nilai perpindahan leleh yang didapatkan untuk ketiga variasi bukaan hampir sama sedangkan nilai kekakuan elastis struktur untuk balok kastella dengan bukaan diamond lebih besar jika dibandingkan dengan balok kastella dengan variasi bukaan circular ataupun bukaan heksagonal walaupun perbedaannya tidak signifikan. Hal ini sejalan dengan penelitian yang telah dilaksanakan oleh Jamadar dan Kumbhar (2015). Setelah nilai perpindahan leleh dari pembebanan monotonik didapatkan, nilai perpindahan leleh tersebut menjadi acuan untuk membuat grafik riwayat pembebanan untuk skema pembebanan siklik quasi-statik dan dikarenakan nilai perpindahan leleh antara ketiga variasi bukaan hampir sama, maka diambil nilai perpindahan leleh yang seragam yaitu sebesar 7,7 $\mathrm{mm}$. Gambar 7 menunjukkan grafik riwayat pembebanan berdasarkan nilai perpindahan leleh yang didapatkan, yang selanjutnya akan digunakan dalam skema pembebanan siklik quasi-statik.

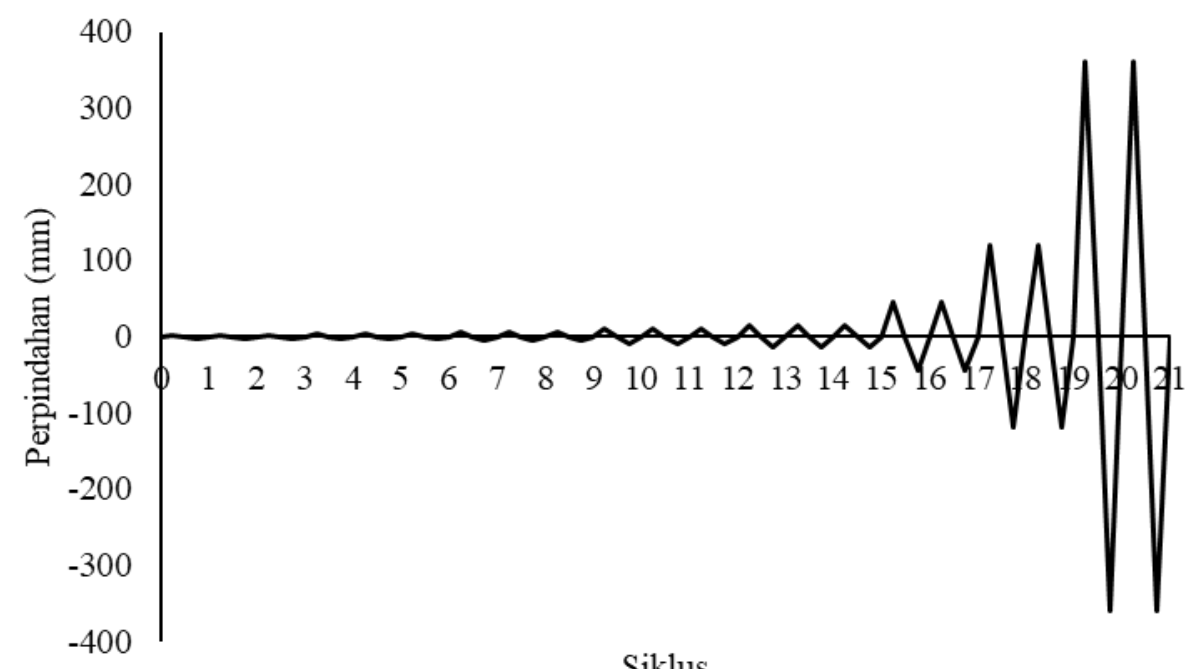

\section{Gambar 7. Grafik riwayat pembebanan untuk beban siklik quasi-statik}

Gambar 8 menunjukkan grafik hubungan gaya reaksi dan perpindahan dari balok kastella dengan variasi bukaan yang dikenai beban siklik quasi-statik sedangkan Tabel 3 menunjukkan karakteristik balok kastella terhadap beban siklik quasi-statik. Dari Gambar 8 dan Tabel 3 dapat terlihat bahwa, pada kondisi awal sampai terjadi kelelehan pertama, karakteristik struktur untuk ketiga variasi bukaan relatif sama. Hal ini ditandai dengan tidak terdapat perbedaan yang cukup signifikan antara nilai perpindahan leleh dari ketiga bukaan tersebut. Kemudian setelah terjadi kelelehan pertama, terjadi perbedaan perilaku inelastik dari masing-masing variasi bukaan. Perbedaan tersebut dimulai pada siklus ke-17 dimana pemberian perpindahan bernilai $120 \mathrm{~mm}$. Nilai kekakuan pasca leleh dari balok kastella dengan bukaan diamond lebih tinggi jika dibandingkan dengan bukaan lainnya, selain itu berdasarkan kurva histerisis yang didapatkan, untuk balok kastella dengan bukaan diamond, luasan kurva histerisis lebih besar jika dibandingkan dengan kedua bukaan lainnya (heksagonal dan circular). Hal ini dikarenakan nilai disipasi energi yang dihasilkan oleh balok kastella dengan bukaan diamond lebih besar jika dibandingkan dengan bukaan lainnya, yaitu 
sebesar 3,0151.105 kN-mm, sehingga dapat disimpulkan bahwa balok kastella dengan bukaan diamond mempunyai kinerja yang lebih baik jika dibandingkan dengan bukaan lainnya terhadap beban siklik quasi-statik.

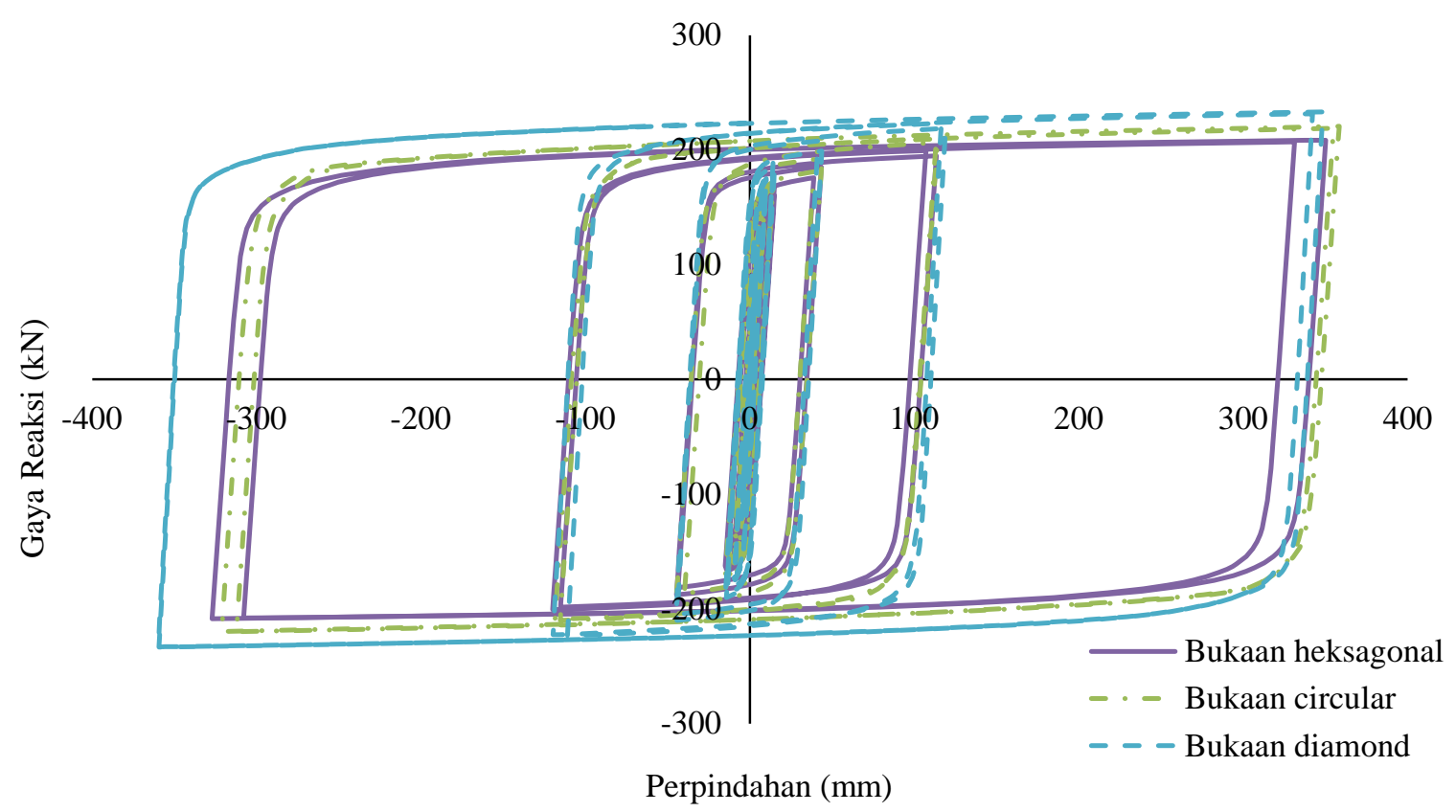

Gambar 8. Hubungan gaya reaksi terhadap perpindahan balok kastella yang dikenai beban siklik quasi-statik

Tabel 3. Karakteristik balok kastella terhadap beban siklik quasi-statik

\begin{tabular}{lccc}
\hline \multicolumn{1}{c}{ Variabel yang ditinjau } & $\begin{array}{c}\text { Bukaan } \\
\text { heksagonal }\end{array}$ & $\begin{array}{c}\text { Bukaan } \\
\text { circular }\end{array}$ & $\begin{array}{c}\text { Bukaan } \\
\text { diamond }\end{array}$ \\
\hline Disipasi energi $(\mathrm{kN}-\mathrm{mm})$ & $2,57944.10^{5}$ & $2,6604.10^{5}$ & $3,0151.10^{5}$ \\
Perpindahan leleh $(\mathrm{mm})$ & 6,9909 & 6,9093 & 6,0256 \\
Gaya reaksi leleh $(\mathrm{kN})$ & 137,0794 & 139,3104 & 149,7079 \\
Perpindahan maksimum $(\mathrm{mm})$ & 350,2518 & 358,3708 & 359,8219 \\
Gaya reaksi maksimum $(\mathrm{kN})$ & 208,5678 & 220,4922 & 233,3372 \\
\hline
\end{tabular}

\section{Kesimpulan}

Penelitian ini meninjau perilaku dari balok kastella dengan variasi bukaan terhadap beban siklik quasi-statik. Tipe bukaan yang ditinjau adalah bukaan heksagonal, bukaan circular, dan bukaan diamond. Analisis yang digunakan adalah analisis elemen hingga dengan menggunakan bantuan perangkat lunak ABAQUS. Model balok yang ditinjau adalah balok di atas dua tumpuan sendi. Pembebanan dilakukan dengan teknik kontrol perpindahan. Berdasarkan hasil yang didapatkan, dapat disimpulkan bahwa balok kastella dengan bukaan diamond mempunyai kinerja yang lebih baik jika dibandingkan dengan bukaan lainnya (heksagonal dan circular) baik terhadap beban monotonik maupun terhadap beban siklik kuasi-statik. Hal ini ditandai dengan nilai kekakuan struktur yang lebih tinggi pada balok kastella dengan bukaan diamond. Selain itu, pada pembebanan siklik kuasi-statik, nilai disipasi energi pada balok kastella dengan bukaan diamond lebih tinggi jika dibandingkan dengan kedua bukaan lainnya. 


\section{Daftar Pustaka}

ABAQUS/Standard, 2016, ABAQUS Analysis User's Guide, Hibbit, Karlsson and Sorenson Inc., Providence, RI.

ABAQUS/Standard, 2005, User's Manual I-III version 6.5, Hibbit, Karlsson and Sorenson Inc., Providence, RI.

Applied Technology Council, 1992, Guidelines for Cyclic Seismic Testing of Components of Steel Structures for Buildings, Report No. ATC-24, Redwood City, CA.

De'nan, F., Keong, C.K., dan Hashim, N. S., 2017, Shapes and Sizes of Web Opening Effects on Bending Behaviour of I-Beam with Web Opening, AIP Conference Proceedings, Volume 1892, Issue 1, pp 1-8.

Deshmukh, N. dan Kasnale, A., 2019, Parametric Study of Castellated Beam with Coupled Stiffener, International Journal of Advance Research, Ideas and Innovations in Technology, Volume 5, Issue 4, pp 86-92.

Dewobroto, W., 2018, Prospek dan Permasalahan Bangunan Baja Tahan Gempa, Seminar Civil Week 2018, Universitas Muhammadiyah Jakarta.

Federal Emergency Management Agency, 2007, Interim Testing Protocols for Determining the Seismic Performance Characteristics of Structural and Nonstructural Components, FEMA Report 461, Washington.

Frans, R., Parung, H., Muhiddin, A.B. dan Irmawaty, R., 2016, Optimization of Short-Span Hexagonal Castellated Beam using Fast Multi Swarm Optimization, International Seminar on Infrastructure Development (Indonesia, 22 September 2016).

Frans, R., Parung, H., Sandy, D. dan Tonapa, S., 2017, Numerical Modelling of Hexagonal Castellated Beam under Monotonic Loading, Procedia Engineering, Volume 171, pp 781788, Elsevier.

Frans, R., Parung, H., Muhiddin, A.B. dan Irmawaty, R., 2018, Study of The Behavior of Composite Castellated Beam, Journal of Engineering and Applied Science, Volume 13, Issue 7, pp 1767-1773.

Govindrao, D.K. dan Rathi, V.R., 2017, Study of Positions of Stiffeners in Sinusoidal Castellated Beam, International Journal of Engineering Sciences \& Research Technology, Volume 6, Issue 2, pp 736-739.

Jamadar, A.M. dan Kumbhar, P.D., 2015, Parametric study of castellated beam with circular and diamond shaped openings, International Research Journal of Engineering and Technology, Volume 2, pp 715-722.

Krawinkler, H., 2009, Loading Histories for Cyclic Tests in Support of Performance Assessment of Structural Components, The 3rd International Conference on Advances in Experimental Structural Engineering (San Fransisco, 15-16 Oktober 2009).

Panedpojaman, P. dan Rongram, T., 2014, Design Equations for Vierendeel Bending of Steel Beams with Circular Web Openings, Proceedings of the World Congress on Engineering 2014, Volume II (London, 2-4 Juli 2014). 
Ravi, P. dan Aiswarya, S., 2018, Performance Analysis of Castellated Beams with Different Web Openings, International Journal of Engineering Research \& Technology, Volume 6, Issue 6, pp 1-3.

Rodrigues, V., Vellasco, P.C.G., Lima, L.R.O. dan Andrade, S.A.L., 2014, Finite Element Modelling of Steel Beams with Web Openings, Engineering, Volume 6, pp 886-913.

Rugge, P.P. dan Pasnur, P.K., 2017, Review on Study of Castellated Beam With \& Without Stiffeners, International Journal of Science Technology \& Engineering, Volume 3, Issue 9, 326-328.

Soltani, M.R., Bouchair, A. dan Mimoune, M., 2012, Nonlinear FE Analysis of the Ultimate Behavior of Steel Castellated Beams, Journal of Construction Steel Research, Volume 70, pp 101-114.

Wakchaure, M.R. dan Sagade, A.V., 2012, Finite Element Analysis of Castellated Steel Beam, International Journal of Engineering and Innovative Technology, Volume 2, Issue 1, pp 365372. 